\title{
Estimativa da incerteza em ensaio de detecção de endotoxina bacteriana pelo método de gelificação
}

\author{
Felipe Rebello Lourenço*, Telma Mary Kaneko, Terezinha de Jesus Andreoli Pinto
}

Departamento de Farmácia, Faculdade de Ciências Farmacêuticas, Universidade de São Paulo

*Correspondência:

F. R. Lourenço

Departamento de

Farmácia-Faculdade

de Ciências Farmacêuticas

USP - Av. Prof. Lineu

Prestes, 580 - Bloco 13

05508-900-São Paulo

SP-Brasil

E-mail: feliperl@usp.br
Desde a publicação da ISO 17025:1999, o interesse em métodos para estimativa da incerteza em ensaios qualitativos, do tipo "passa/ não passa", têm ganho grande importância. Uma forma de estimar e informar a incerteza deste tipo de ensaio é o uso das probabilidades de respostas-falsas, particularmente falsos-positivos e falsos-negativos, determinados a partir do teorema de Bayes. $O$ objetivo deste artigo é estabelecer um método para a estimativa de incerteza em ensaios de detecção de endotoxina bacteriana pelo método in vitro Limulus Amebocyte Lysate $(L A L)$. Considerando a confirmação da sensibilidade do LAL e a validação do teste, a probabilidade de uma resposta falsa corresponde à soma da probabilidade dos resultados falso-negativos e falso-positivos. A partir dos resultados obtidos foi verificado que a etapa da confirmação da sensibilidade do LAL contribui para a incerteza de forma mais significativa (67,6\%) que a etapa de validação do teste $(32,4 \%)$. Através de um procedimento simples, descrito neste artigo, e de dados obtidos a partir da confirmação da sensibilidade do LAL e validação do teste para um produto em questão é possível obter uma estimativa de incerteza razoável para o ensaio de detecção de endotoxinas bacterianas pelo método de gelificação.

\author{
Unitermos \\ - Incerteza \\ - Endotoxina Bacteriana \\ - LAL \\ - Validação \\ - ISO 17025
}

\section{INTRODUÇÃO}

Desde a publicação da ISO 17025:1999, o interesse por métodos de estimativa da incerteza de medição tem crescido consideravelmente e as dificuldades em ensaios qualitativos, do tipo "passa/não passa", têm ganho importância. Uma forma de estimar e informar a incerteza deste tipo de ensaio é o uso das probabilidades de respostas falsas, particularmente falsos-positivos e falsos-negativos (Ellison, 2000). O ensaio para a detecção de endotoxina bacteriana pelo método de gelificação é um exemplo em que estes procedimentos se aplicam.

As endotoxinas são lipopolissacarídeos (LPS) associados à membrana externa de bactérias Gram negativas, e se constituem na mais significante fonte de pirogênio para a industria farmacêutica (Pinto et al., 2003). O LAL (Limulus Amebocyte Lysate) é um produto derivado do lisado de amebócitos do caranguejo Limulus polyphemus, com emprego específico na determinação de endotoxinas bacterianas derivadas de bacilos Gram- negativos, entre 
outros pelo método da formação de gel. Este indica uma resposta para a presença de endotoxina na amostra contendo quantidade igual ou superior à sua sensibilidade $(\mathrm{O})$ (Pinto et al., 2003). A reação do LAL requer um pH neutro e é dependente do tempo, da temperatura e concentração da endotoxina (United States Pharmacopeia, 2004).

A inibição ou a potencialização da resposta também devem ser consideradas. A avaliação destes efeitos é efetuada contaminando-se a amostra na diluição em que é testada com quantidades determinadas de endotoxina bacteriana, de forma a permitir verificar se a amostra interfere (inibe ou potencializa) a reação de formação do gel (Farmacopéia Brasileira, 1996). Os resultados obtidos em três lotes diferentes de um produto devem ser adequados para que o método possa ser considerado validado para o produto em questão.

O objetivo deste artigo é estabelecer procedimento para a estimativa de incerteza em ensaios de detecção de endotoxina bacteriana, pelo método de gelificação, a partir dos resultados obtidos durante a validação do teste para um determinado produto. Neste artigo, apresentam-se os resultados de validação de cefazolina para injeção e utiliza-se este produto como exemplo para a estimativa de incerteza.

\section{MATERIAL E MÉTODOS}

Trabalhou-se com o produto injetável de cefazolina, testado com reagente LAL (Endosafe, 0,125 UE/mL) e endotoxina padrão de controle (CSE Endosafe). As amostras e controles foram diluídos em água reagente para LAL. Uma porção de $0,1 \mathrm{~mL}$ das soluções contendo endotoxina bacteriana foram misturadas com $0,1 \mathrm{~mL}$ de LAL em tubos apirogênicos (10 $\mathrm{mm} \times 75 \mathrm{~mm})$ e incubados a $37 \pm 1{ }^{\circ} \mathrm{C}$ por $60 \pm 2$ minutos em banho-maria (Unique modelo: USC2800A)

\section{Determinação da MDV}

A máxima diluição válida (MDV) é a diluição máxima permitida para um produto com um determinado limite de especificação para que a endotoxina bacteriana, caso presente, possa ser detectada. A equação geral para a determinação da MDV é (United States Pharmacopeia, 2004):

$$
\mathrm{MDV}=\frac{\mathrm{L} \times \mathrm{C}}{\mathrm{O}}
$$

onde: $\mathrm{L}=$ limite de especificação da monografia $\mathrm{C}=$ concentração do fármaco e $\mathrm{O}=$ sensibilidade do LAL.
O limite de endotoxina bacteriana para cefazolina é de 0,15 unidades endotóxicas (UE) por mg de cefazolina (United States Pharmacopeia, 2004). Desta forma, para uma solução com $100 \mathrm{mg} / \mathrm{mL}$ de cefazolina, a MDV é de 120x. A diluição escolhida para o teste foi de 100x. Com esta diluição a substância ativa não apresenta interferência e está numa concentração de $1 \mathrm{mg} / \mathrm{mL}$ (Yamamoto et al., 2000).

\section{Sensibilidade do LAL}

A sensibilidade (O) do LAL foi confirmada através de uma série de diluições de endotoxina bacteriana com concentrações de $2 \mathrm{O}, \mathrm{O}, 1 / 2 \mathrm{Oe} 1 / 4 \mathrm{O}$. O teste foi realizado em quadruplicata. A média geométrica (MG) das concentrações de ponto final deve estar entre $1 \frac{1}{2} \mathrm{Oe} 2 \mathrm{O}$ (Farmacopéia Brasileira, 1996).

$$
M G=\operatorname{antilog}\left(\begin{array}{ll}
1 & e / f
\end{array}\right)
$$

onde: $\mathrm{e}=$ somatória do logaritmo dos pontos finais e $\mathrm{f}=$ número de réplicas.

\section{Validação do Teste}

A validação do teste é realizada através da inibição ou potencialização da reação de formação do gel (Pinto et al., 2003). Este teste foi realizado para três lotes diferentes de cefazolina para injeção. Para cada um destes lotes foram preparadas as soluções indicadas na Tabela I. Procedeu-se ao trabalho experimental, obedecendo a critério de ensaios independentes a cada uma das réplicas ensaiadas, conforme orientação da United States Pharmacopeia 2004, empregando-se 4 réplicas.

Quando há inibição da formação de gel, ou seja, quando há quantidade suficiente para ocorrer formação de gel, porém a amostra impede a sua formação, tem-se média geométrica maior que a sensibilidade do LAL. No caso de potencialização da reação de formação de gel, ou seja, quando ocorrer formação de gel mesmo sem haver quantidade de endotoxina suficiente, tem-se média geométrica menor que a sensibilidade do LAL. Para que o teste seja considerado válido quanto à inibição e potencialização da formação de gel a média geométrica das concentrações de ponto final deve estar entre $1 / 2 \mathrm{O}$ e $2 \mathrm{O}$ (Farmacopéia Brasileira, 1996).

Após a validação do teste, este pode ser aplicado à rotina de trabalho para a aprovação ou rejeição dos lotes produzidos. O teste é usado quando a monografia apresenta as especificações para o limite de endotoxina e, na situação de escolha entre os diferentes métodos (gelificação, fotométrico e turbidimétrico), a decisão final é 
baseado no ensaio de gelificação (United States Pharmacopeia, 2004). No teste de rotina são preparadas as soluções indicadas na Tabela II.

Para o ensaio ser considerado válido ambas as duplicatas das soluções controle positivo B e C devem ser positivos e da solução controle negativo $\mathrm{D}$ devem ser negativos. A amostra testada é considerada aprovada quando o teste é valido e ambas as replicatas da solução teste A for negativo. No caso de resultado positivo de ambas as replicatas da solução teste $\mathrm{A}$, a amostra pode ser retestada numa diluição maior, contanto que não exceda a MDV (Farmacopéia Brasileira, 1996).

\section{Análise Estatística}

A definição dos parâmetros de performance é um aspecto importante a ser considerado quando se trabalha com ensaios qualitativos. Nestes, avaliam-se os parâmetros de exatidão, precisão e incerteza através da sensibilidade, especificidade e probabilidades de falsosnegativo e falsos-positivo (Trullols et al., 2004).
- Probabilidade de falso-negativo: é "a probabilidade de um teste ser classificado como negativo, sendo que a amostra é positiva".

- Probabilidade de falso-positivo: é "a probabilidade de um teste ser classificado como positivo, sendo que a amostra é negativa".

- Sensibilidade: é a "habilidade do método detectar uma amostra verdadeiramente positiva como positivo".

- Especificidade: é a "habilidade do método detectar uma amostra verdadeiramente negativa como negativo".

\section{RESULTADOS E DISCUSSÃO}

Os resultados obtidos durante a confirmação da sensibilidade do LAL estão apresentados na Tabela III.

Os resultados obtidos durante a validação do teste estão apresentados nas Tabelas IV, V e VI e aqueles obtidos durante o trabalho de rotina para uma amostra de cefazolina para injeção estão apresentados na Tabela VII.

Os dados para construção da Tabela VIII, obedecendo ao teorema de Bayes (Ellison et al., 1998), foram ob-

TABELA I - Teste de inibição e potencialização da formação de gel para cefazolina

\begin{tabular}{lcccc}
\hline Solução & Análise & $\begin{array}{c}\text { Concentração } \\
\text { de endotoxina }\end{array}$ & $\begin{array}{c}\text { Concentração } \\
\text { de cefazolina }\end{array}$ & $\begin{array}{c}\text { Número de } \\
\text { réplicatas }\end{array}$ \\
\hline $\mathrm{A}$ & cefazolina & - & $1 \mathrm{mg} / \mathrm{mL}$ & 4 \\
$\mathrm{~B}$ & cefazolina & $2 \mathrm{O}$ & $1 \mathrm{mg} / \mathrm{mL}$ & 4 \\
& + & $\mathrm{O}$ & $1 \mathrm{mg} / \mathrm{mL}$ & 4 \\
& endotoxina & $1 / 2 \mathrm{O}$ & $1 \mathrm{mg} / \mathrm{mL}$ & 4 \\
$\mathrm{C}$ & & $1 / 4 \mathrm{O}$ & $1 \mathrm{mg} / \mathrm{mL}$ & 4 \\
& endotoxina & $2 \mathrm{O}$ & - & 4 \\
& & $\mathrm{O}$ & - & 4 \\
$\mathrm{D}$ & $1 / 2 \mathrm{O}$ & - & 4 \\
\hline
\end{tabular}

Solução A: Amostra testada; Solução B: Controle positivo da amostra (validação do teste); Solução C: Controle positivo da CSE (Confirmação da sensibilidade do LAL); Solução D: Controle negativo

TABELA II - Trabalho de rotina para cefazolina

\begin{tabular}{lcccc}
\hline Solução & análise & $\begin{array}{c}\text { Concentração } \\
\text { de endotoxina }\end{array}$ & $\begin{array}{c}\text { Concentração } \\
\text { de cefazolina }\end{array}$ & $\begin{array}{c}\text { Número de } \\
\text { replicatas }\end{array}$ \\
\hline A & cefazolina & - & $1 \mathrm{mg} / \mathrm{mL}$ & 2 \\
$\mathrm{~B}$ & cefazolina + endotoxina & $2 \mathrm{O}$ & $1 \mathrm{mg} / \mathrm{mL}$ & 2 \\
$\mathrm{C}$ & endotoxina & $2 \mathrm{O}$ & - & 2 \\
$\mathrm{D}$ & água & - & - & 2 \\
\hline
\end{tabular}

Solução A: Amostra testada; Solução B: Controle positivo da amostra; Solução C: Controle positivo da CSE; Solução D: Controle negativo 
TABELA III - Confirmação da sensibilidade do LAL (Solução C)

\begin{tabular}{lccccc}
\hline \multicolumn{7}{c}{ Endotoxina } \\
Tubo & $\mathbf{2 0}$ & $\mathbf{O}$ & $\mathbf{1} \mathbf{2} \mathbf{O}$ & $\mathbf{1} / \mathbf{0}$ & $\mathbf{P F}$ \\
\hline 1 & $(+)$ & $(+)$ & $(-)$ & $(-)$ & $\mathrm{O}$ \\
2 & $(+)$ & $(+)$ & $(-)$ & $(-)$ & $\mathrm{O}$ \\
3 & $(+)$ & $(+)$ & $(+)$ & $(-)$ & $1 / 2 \mathrm{O}$ \\
4 & $(+)$ & $(+)$ & $(-)$ & $(-)$ & $\mathrm{O}$ \\
\hline
\end{tabular}

MG: $0,8 \mathrm{O}$

O. Sensibilidade do LAL; PF: Ponto final; MG: Média Geométrica

tidos a partir dos resultados da confirmação da sensibilidade do LAL e da validação de teste. Nessa tabela estão identificados todos os resultados possíveis encontrados e suas somas, conforme apresentado na Tabela VIII.

Os resultados verdadeiramente positivos (A) são aqueles em que, tendo uma quantidade suficiente de endotoxina, ocorreu formação de gel. Os resultados falsopositivos (B), são aqueles nos quais na prática ocorreu for-

TABELA IV - Validação do primeiro lote cefazolina para injeção (Solução B)

\begin{tabular}{lccccc}
\hline \multicolumn{7}{c}{ Cefazolina + Endotoxina } \\
Tubo & $\mathbf{2 0}$ & $\mathbf{O}$ & $1 / 2 \mathbf{O}$ & $1 / 4 \mathbf{O}$ & $\mathbf{P F}$ \\
\hline 1 & $(+)$ & $(+)$ & $(+)$ & $(-)$ & $1 / 2 \mathrm{O}$ \\
2 & $(+)$ & $(+)$ & $(+)$ & $(-)$ & $1 / 2 \mathrm{O}$ \\
3 & $(+)$ & $(+)$ & $(+)$ & $(-)$ & $1 / 2 \mathrm{O}$ \\
4 & $(+)$ & $(+)$ & $(+)$ & $(-)$ & $1 / 2 \mathrm{O}$ \\
\hline MG: $0,5 \mathrm{O}$ & & & & &
\end{tabular}

O. Sensibilidade do LAL; PF: Ponto final; MG: Média Geométrica

TABELA V - Validação do segundo lote cefazolina para injeção (Solução B)

\begin{tabular}{lccccc}
\hline \multicolumn{7}{c}{ Cefazolina + Endotoxina } \\
Tubo & $\mathbf{2 0}$ & $\mathbf{O}$ & $\mathbf{1} / 2 \mathbf{O}$ & $1 / 4 \mathrm{O}$ & $\mathbf{P F}$ \\
\hline 1 & $(+)$ & $(+)$ & $(+)$ & $(-)$ & $1 / 2 \mathrm{O}$ \\
2 & $(+)$ & $(+)$ & $(+)$ & $(-)$ & $1 / 2 \mathrm{O}$ \\
3 & $(+)$ & $(+)$ & $(+)$ & $(-)$ & $1 / 2 \mathrm{O}$ \\
4 & $(+)$ & $(+)$ & $(+)$ & $(-)$ & $1 / 2 \mathrm{O}$ \\
\hline MG: $0,5 \mathrm{O}$ & & & & &
\end{tabular}

MG: 0,50

O. Sensibilidade do LAL; PF: Ponto final; MG: Média Geométrica mação de gel, porém não havia quantidade de endotoxina suficiente. Os resultados falso-negativo (C) são aqueles em que, apesar de ter uma quantidade de endotoxina suficiente, não ocorre formação de gel. Finalmente, os resultados verdadeiramente negativos (D) são aqueles em que não ocorreu formação de gel porque não havia quantidade de endotoxina suficiente para tal. Estes resultados verdadeiros e falsos foram determinados em função da média geométrica.

Contando-se o número de tubos com resultados verdadeiramente positivos, falso-positivos, falso-negativos e verdadeiramente negativos obtidos nos procedimentos de confirmação da sensibilidade do LAL e da validação do teste (para os três lotes) pôde-se elaborar, respectivamente, as Tabelas IX e X.

Desta forma, aplicando as equações 1 e 2 aos resultados obtidos nas Tabelas IX e X determina-se as probabilidades de falso-negativos e falso-positivos para a confirmação da sensibilidade do LAL e a validação do teste, conforme apresentado na Tabela XI.

As probabilidades de resultados falso-negativos e falso-positivo podem ser determinadas de acordo com as

TABELA VI - Validação do terceiro lote cefazolina para injeção (Solução B)

\begin{tabular}{lccccc}
\hline \multicolumn{7}{c}{ Cefazolina + Endotoxina } \\
Tubo & $\mathbf{2 0}$ & $\mathbf{O}$ & $\mathbf{1} / 2 \mathbf{O}$ & $\mathbf{1} / \mathbf{O}$ & $\mathbf{P F}$ \\
\hline 1 & $(+)$ & $(+)$ & $(+)$ & $(-)$ & $1 / 2 \mathrm{O}$ \\
2 & $(+)$ & $(+)$ & $(+)$ & $(-)$ & $1 / 2 \mathrm{O}$ \\
3 & $(+)$ & $(+)$ & $(+)$ & $(-)$ & $1 / 2 \mathrm{O}$ \\
4 & $(+)$ & $(+)$ & $(-)$ & $(-)$ & $\mathrm{O}$ \\
\hline MG: $0,6 \mathrm{O}$ & & & & &
\end{tabular}

O. Sensibilidade do LAL; PF: Ponto final; MG: Média Geométrica

TABELA VII - Resultados referente à amostra de cefazolina para injeção

\begin{tabular}{lcccc}
\hline \multicolumn{5}{c}{ Cefazolina + Endotoxina } \\
Tubo Solução A & Solução B & Solução C & Solução D \\
\hline 1 & $(-)$ & $(+)$ & $(+)$ & $(-)$ \\
2 & $(-)$ & $(+)$ & $(+)$ & $(-)$ \\
\hline
\end{tabular}

Teste: Válido; Amostra: Aprovada; (-) Resultado negativo; $(+)$ Resultado positivo 
TABELA VIII - Teorema de Bayes

\begin{tabular}{lccc}
\hline Prática & $(+)$ & $\begin{array}{c}\text { Teoria } \\
(-)\end{array}$ & Soma \\
\hline$(+)$ & A & B & A + B \\
$(-)$ & C & D & C + D \\
Soma & A + C & B + D & A + B + C + D \\
\hline
\end{tabular}

A: Resultados verdadeiramente positivos

$\mathrm{A}+\mathrm{B}$ : Total de resultados experimentalmente positivos

B: Resultados falso-positivos

C + D: Total de resultados experimentalmente negativos

C: Resultados falso-negativos

A + C: Total de resultados teoricamente positivos

D: Resultados verdadeiramente negativos

$\mathrm{B}+\mathrm{D}$ : Total de resultados teoricamente negativos

$\mathrm{A}+\mathrm{B}+\mathrm{C}+\mathrm{D}$ : Total de resultados verdadeiros e falsos.

Equações 1 e 2:

Falso-positivo: $\quad \mathrm{P}_{\mathrm{F}+}=\frac{\mathrm{B}}{(\mathrm{A}+\mathrm{B})}$

(Equação 1)

Observação: Corresponde à probabilidade de um resultado ser negativo, sabendo que na prática o teste foi positivo.

Falso-negativo: $\quad \mathrm{P}_{\mathrm{F}-}=\frac{\mathrm{C}}{(\mathrm{C}+\mathrm{D})}$

(Equação 2)

Observação: Corresponde à probabilidade de um resultado ser positivo, sabendo que na prática o teste foi negativo.

Os índices de sensibilidade e especificidade podem

TABELA IX - Confirmação da sensibilidade do LAL conforme o teorema de Bayes

\begin{tabular}{lccc}
\hline Prática & $(+)$ & $\begin{array}{c}\text { Teoria } \\
(-)\end{array}$ & Soma \\
\hline$(+)$ & 8 & 1 & 9 \\
$(-)$ & 0 & 7 & 7 \\
Soma & 8 & 8 & 16 \\
\hline
\end{tabular}

ser determinados de acordo com as Equações 3 e 4:

Sensibilidade: $\quad \mathrm{S}=\frac{\mathrm{A}}{(\mathrm{A}+\mathrm{C})}$

(Equação 3)

Observação: Corresponde à probabilidade de uma amostra ser positiva, sabendo que o teste foi positivo.

Especificidade: $\quad \mathrm{E}=\frac{\mathrm{D}}{(\mathrm{B}+\mathrm{D})}$

(Equação 4)

Observação: Corresponde à probabilidade de uma amostra ser negativa, sabendo que o teste foi negativo.

Considerando a confirmação da sensibilidade do LAL e a validação do teste, a probabilidade de uma resposta falsa corresponde a soma da probabilidade dos resultados falso-negativos e falso-positivos. Levando-se em conta que, no trabalho de rotina, cada solução (A, B, C e D) é testada em duplicata, então as probabilidades apresentadas na Tabela VI devem ser elevadas ao quadrado (Beiguelman, 2002). Portanto, a incerteza do ensaio de detecção de endotoxinas bacterianas pelo método de gelificação pode ser estimada conforme a Equação 5. O teste presenta sensibilidade de $100 \%$ para confirmação do LAL e $97 \%$ para a validação do teste e especificidade de $88 \%$ para a confirmação do LAL e $100 \%$ para a validação do teste.

$\mathrm{U}=\left(\mathrm{P}_{\mathrm{F} / \mathrm{LAL}}+\mathrm{P}_{\mathrm{F} / \text { Valid }}\right) \times 100=\left(\mathrm{P}_{\mathrm{F}+/ \mathrm{LAL}}^{2}+\mathrm{P}_{\mathrm{F}-/ \mathrm{LAL}}^{2}\right)+$
$\left(\mathrm{P}_{\mathrm{F}+/ \text { Valid }}^{2}+\mathrm{P}_{\mathrm{F}-/ \text { Valid }}^{2}\right) \times 100$
(Equação 5)

Onde: $\mathrm{P}_{\mathrm{F} / \mathrm{LAL}}=$ probabilidade de um resultado falso referente à confirmação da sensibilidade do LAL; $\mathrm{P}_{\mathrm{F}+\mathrm{LAL}}=$ probabilidade de um falso-positivo referente à confirmação da sensibilidade do LAL; $\mathrm{P}_{\mathrm{F}-\mathrm{L} \text { AL }}$ = probabilidade de um falso-negativo referente à confirmação da sensibilidade do LAL;

TABELA X - Validação do teste conforme o teorema de Bayes

\begin{tabular}{lccc}
\hline Prática & $\left(\begin{array}{c}\text { Teoria } \\
(-)\end{array}\right.$ & Soma \\
\hline$(+)$ & 35 & 0 & 35 \\
$(-)$ & 1 & 12 & 13 \\
Soma & 36 & 12 & 48 \\
\hline
\end{tabular}

TABELA XI - Probabilidade de resultados falso-positivos, falso-negativos, sensibilidade e especificidade

\begin{tabular}{|c|c|c|c|c|}
\hline & Falso-positivo $\left(P_{F+}\right)$ & Falso-negativo $\left(\mathrm{P}_{\mathrm{F}-}\right)$ & Sensibilidade & Especificidade \\
\hline Confirmação da sensibilidade & 0,11 & 0,00 & 1,00 & 0,88 \\
\hline Validação do teste & 0,00 & 0,08 & 0,97 & 1,00 \\
\hline
\end{tabular}


$\mathrm{P}_{\mathrm{F} / \text { Valid }}=$ probabilidade de um resultado falso referente à validação do teste; $\mathrm{P}_{\mathrm{F}+\text { /Valid }}=$ probabilidade de um falso-positivo referente à validação do teste e $\mathrm{P}_{\mathrm{F}-\text { /Valid }}=$ probabilidade de um falso-negativo referente à validação do teste.

A partir do exemplo da cefazolina para injeção, temos o cálculo da incerteza (U) (Equação 6):

$\mathrm{U}=\left(0,11^{2}+0,00^{2}\right)+\left(0,00^{2}+0,08^{2}\right) \times 100=1,2 \%+0,6 \%$ $=1,8 \%$

(Equação 6)

\section{CONCLUSÕES}

Considerando o valor da incerteza estimado $(1,8 \%)$, $1,2 \%$ (equivalente $67,6 \%$ ) do mesmo tem origem na confirmação da sensibilidade do LAL e $0,6 \%$ (equivalente a $32,4 \%$ ) corresponde à validação do teste. A contribuição de incerteza devido à sensibilidade do LAL pode ser diminuída com o aumento do número de réplicas durante a realização do teste.

A incerteza indica a probabilidade do teste ter falhado (resultados falso-positivo e falso-negativo), mas não indica a probabilidade da amostra estar fora da especificação. Também vale lembrar que as probabilidades de falso-positivos e falso-negativos se aplicam à diluição em que a validação foi realizada. Numa outra diluição a interferência da amostra pode ser diferente, resultando em probabilidades e, conseqüentemente, estimativas de incerteza diferentes. De acordo com os índices de sensibilidade e especificidade, pode-se concluir que o teste é adequado para a finalidade proposta.

Portanto, a partir de um procedimento simples e de dados obtidos a partir da confirmação da sensibilidade do LAL e validação do teste para um produto em questão é possível obter uma estimativa de incerteza razoável para o ensaio de detecção de endotoxinas bacterianas pelo método de gelificação.

\section{ABSTRACT \\ Estimation of uncertainty in the detection of bacterial endotoxin by gel-clot method}

Since the publication of ISO 17025:1999, the interest in methods for estimation of the uncertainty in qualitative analysis, such as 'pass/fail', have became more important. The usual form of estimating and informing the uncertainty in this kind of analysis is the use of false-response rates, particularly false-positive and false-negative, determinated from Bayes theorem. The aim of this paper is establish a method for estimation of the uncertainty in the detection of bacterial endotoxins by in vitro Limulus Amebocyte Lysate ( $L A L)$ test. Considering the confirmation of $L A L$ sensitivity and the validation of the test, the probability of a false-response corresponds to the sum of falsenegative and false-positive result probabilities. From results obtained was verified that the confirmation of LAL sensitivity contributed to the uncertainty in a more significant way $(67,6 \%)$ than the validation of the test (32,4\%). Through this simple procedure and data obtained from the confirmation of LAL sensibility and the validation of the test is possible to obtain a reasonable estimation of the uncertainty of the detection of bacterial endotoxins by gel-clot test.

UNITERMS: Uncertainty. Bacterial endotoxins. LAL. Validation. ISO 17025.

\section{AGRADECIMENTOS}

Ao Laboratório de controle de qualidade de medicamentos, cosméticos, domissanitários, produtos afins e as respectivas matérias-primas (CONFAR) e à Fundação Instituto de Pesquisas Farmacêuticas (FIPFARMA) pelo auxílio técnico, científico e financeiro.

\section{REFERÊNCIAS}

BEIGUELMAN, B. O Cálculo de probabilidades. In: BEIGUELMAN, B., ed. Curso prático de bioestatística. Ribeirão Preto: FUNPEC Editora, 2002. p. 37-72.

BRITSH pharmacopeia 2000. Volume II - Supplementary Chapters - C. Bacterial Endotoxins Test.

CALLEGARI-JACQUES, S. M. Probabilidade em variáveis qualitativas. In: CALLEGARI-JACQUES, S. M. Bioestatística: Princípios e Aplicações. Porto Alegre: Artmed, 2003.p. 111-118.

DING, J. L.; HO, B. A New era in pyrogen testing. Trends Biotechnol., v.19 n.8, p.277-281, 2001.

European co-operation for accreditation, EA-4/10, Accreditation for Microbiological Laboratories, EA, 2002.

ELLISON, S. L. R. Uncertainties in qualitative testing and analysis. Accred. Qual. Assur., v.5, p.346-348, 2000.

ELLISON, S. L. R.; GREGORY, S.; HARDCASTLE, W. A. Quantifying uncertainty in qualitative analysis. The Analyst, v.123, p.1155-1161, 1998. 
FARMACOPEIA BRASILEIRA. Parte I - Métodos gerais, 4. ed. São Paulo: Atheneu, 1988. V.5.1.9.1-3.

HAISHIDA, Y.; HASEGAWA, C.; YAGAMI, T.; TSUCHIYA, T.; MATSUDA, R.; HAYASHI, Y. Estimation of uncertainty in kinetic-colorimetric assay of bacterial endotoxins. J. Pharm. Biomed. Anal., v.32, p.495-503, 2003.

International Organization for Standardization, ISO/IEC 17025, General requirements for the competence of testing and calibration laboratories, ISO, Geneva, Switzerland, 1999.

PEARSON, F. C. Pyrogens: Endotoxins, LAL testing and depyrogenation. New York: Marcel Dekker, 1985.

PINTO, T. J. A.; KANEKO, T. M.; OHARA, M. T. Pirogênio In: PINTO, T. J. A.; KANEKO, T. M.; OHARA, M. T. Controle biológico de qualidade de produtos farmacêuticos, correlatos e cosméticos. São Paulo: Atheneu Editora, 2003. p.179-216.
USP. UNITED States Pharmacopeia. 27. ed. Rockville: United States Pharmacopeial Convention, 2004, p.21692173.

TRULLOLS, E.; RUISÁNCHEZ, I.; RIUS, F. X. Validation of qualitative analytical methods. Trends in analytical chemistry, v.23, n.2, p.137-145, 2004.

YAMAMOTO, A.; OCHIAI, M.; FUJIWARA, H.; ASAKAWA, S.; ICHINOCHE, K.; KATAOKA, M.; TOYOIZUMI, H.; HORIUCHI, Y. Evaluation of the applicability of the bacterial endotoxin test to antibiotic products. Biologicals, v.28, p.155-167, 2000.

ZIJLSTRA, S.; GERKEN, P.; RECHIN, C.; WORTMANN, R.; NOTOHAMIPRODJO, G. Validation of the Limulus Amebocyte Lysate (LAL) test for routine PET radiopharmaceuticals. Apll. Radiot. Isto., v.48, n.1, p.5154, 1997.

Recebido para publicação em 29 de abril de 2004. Aceito para publicação em 29 de setembro de 2004. 